\title{
ESTRATÉGIAS DE ENFRENTAMENTO E IDEAÇÃO SUICIDA EM CUIDADORES DE CRIANÇAS COM DOENÇA CRÔNICA
}

\author{
Gabriela Falleiros Wirth Chaibub \\ Marina Kohlsdorf \\ (Centro Universitário UniCeub - Brasília)
}

\begin{abstract}
Resumo
Este trabalho analisou estratégias de enfrentamento, depressão e ideação suicida em cuidadores de crianças hospitalizadas com doenças crônicas. Participaram 15 acompanhantes que responderam o Inventário de Depressão de Beck (BDI) e o Inventário de Ideação Suicida de Beck (BSI) e, desses, 8 foram entrevistados individualmente a partir de um roteiro de perguntas semiestruturado. Resultados mostram que os cuidadores apresentam estratégias de enfrentamento focalizadas na religião e apenas duas participantes indicaram depressão severa e ideação suicida. Não foram evidenciadas associações estatisticamente significativas entre os escores do BDI, BSI e os dados sociodemográficos. Conclui-se que é de grande relevância o trabalho multiprofissional dirigido a esses cuidadores para a criação de estratégias de enfrentamento adaptativas e diminuição de manifestações depressivas e/ou ideação suicida.
\end{abstract}

Palavras-chave: estratégias de enfrentamento; depressão; ideação suicida.

\begin{abstract}
Coping and suicidal ideation in caregivers of children with chronic diseases

This study aimed to analyze coping strategies, depression, and suicidal ideation in caregivers of hospitalized children with chronic diseases. Fifteen participants, who responded to the Beck Depression Inventory (BDI) and the Beck Suicidal Ideation Inventory (BSI), were interviewed, and of these, 8 were individually interviewed using a semi-structured questionnaire. Results show that caregivers presented coping strategies focused on religion and only two participants indicated severe depression and suicidal ideation. There were no statistically significant associations between BDI, BSI and sociodemographic data. It is concluded that the multiprofessional work directed to these caregivers is of great relevance for the creation of adaptive coping strategies and the reduction of depressive manifestations and / or suicidal ideation.
\end{abstract}

Keywords: coping, depression, suicidal ideation.

\section{Introdução}

Saúde é definida pela Organização Mundial de Saúde como "um estado de completo bem-estar físico, mental e social, 
e não simplesmente como a ausência de doenças ou enfermidades". Envolve, portanto, três domínios: saúde física, saúde psicológica e saúde social, sendo que cada um destes será influenciado pelos demais (OMS, 2016). A Psicologia da Saúde é um subtema da psicologia que procura a melhoria, tratamento e prevenção de doenças por meio de princípios psicológicos básicos.

Segundo Bowling (2002), citada por Castro (2007), a pesquisa em saúde deve entender o adoecimento das pessoas, sua percepção, as estratégias de enfrentamento, como se comportam e como está o relacionamento com a equipe de saúde. Portanto, esses estudos devem seguir o modelo biopsicossocial, abordando os aspectos biológicos, psicológicos, sociais e culturais.

Spink (1992) apresenta o caminho que a Psicologia percorreu para conquistar seu espaço no campo da saúde. Até pouco tempo, a Psicologia tinha apenas duas áreas: o trabalho exercido em consultórios e o trabalho em hospitais e ambulatórios de saúde mental, seguindo paradigmas da Psiquiatria, focando em internação e medicação.

Essa perspectiva psiquiátrica dentro do contexto hospitalar começou a mudar um pouco com o trabalho em clínicasescola, em que $\mathrm{o}$ atendimento para pessoas menos favorecidas proporcionou a reflexão do conceito de saúde mental em Psicologia. Os psicólogos começaram a trabalhar junto com os médicos, sendo facilitadores nos processos de tratamento, cirurgia, internações e contenção de pacientes nos momentos que expressam suas emoções. Portanto, o trabalho do psicólogo ainda manteve a perspectiva médica e a sua subordinação a ele, porém com um trabalho mais voltado para o indivíduo e seu processo de saúde-doença (Spink, 1992).

No Brasil, começou a ocorrer uma mudança no trabalho do psicólogo nos serviços de saúde em 1982, em São Paulo, sob a influência do trabalho de Franco Basaglia na Itália. Foi adotada pela Secretaria de Saúde uma política pela desospitalização e extensão dos serviços de saúde mental à rede básica. Essa política gerou a criação de equipes de saúde mental integradas, contando com um psiquiatra, um assistente social e um psicólogo, atuando nos centros de saúde do Estado nos níveis primário, secundário e terciário (Spink, 1992).

A autora relata que a inserção dessas equipes não foi fácil, pois houve resistência pelos outros profissionais e os próprios psicólogos não sabiam o que fazer naquele contexto, principalmente porque na graduação não tiveram contato com essa experiência. 
Existem três problemas que dificultam a inserção adequada da Psicologia da Saúde, mas que já estão em fase de melhoria: a graduação em Psicologia, que abarcava apenas aplicações clínicas na área da saúde mental e não abordava temas relacionados à Saúde Pública; o tratamento desvinculado do contexto social do indivíduo, desconsiderando que questões socioeconômicas interferem nos fenômenos psicológicos; e a perspectiva médica, que avalia o paciente pelo seu comportamento em função da adequação médica (Spink, 1992).

Marteau e Johnson (1987) citados em Spink (1992), expuseram sua crença de que o trabalho do psicólogo tem sido mais reconhecido nos contextos de saúde na Inglaterra pela insatisfação com a Medicina Moderna, em que não se consideram aspectos psicológicos, sociais e econômicos, o que, acredita-se, pode valer para o Brasil também.

$\mathrm{Na}$ Psicologia da Saúde, o profissional é centrado nas intervenções primária, secundária e terciária, podendo atuar, então, em contexto hospitalar e de âmbito social, fundamentado na promoção e educação da saúde. Já o profissional que atua em hospitais é focado "nos âmbitos secundário e terciário de atenção à saúde, atuando em instituições de saúde e realizando atividades como: atendimento psicoterapêutico; grupos psicoterapêuticos; grupos de psicoprofilaxia; atendimentos em ambulatório e unidade de terapia intensiva; pronto atendimento; enfermarias em geral; psicomotricidade no contexto hospitalar; avaliação diagnóstica; psicodiagnóstico; consultoria e interconsultoria" (CFP, 2003a, citado por Castro \& Bornholdt, 2004, p.50). De modo específico, a atuação em hospitais comumente se caracteriza pelo acompanhamento de doenças crônicas, que impõem desafios importantes à prática do profissional tendo em vista as demandas do tratamento e sintomatologia.

A doença crônica pode ser caracterizada pela sua longa duração, ou seja, passando de três meses consecutivos ou que exija internação por um período superior a um mês (Barros, 2003; Vieira \& Lima, 2002). Almeida, Higarashi, Molina, Marcon e Vieira (2006) e também Vieira e Lima (2002) apresentam em seus trabalhos as três fases na história da doença crônica: 1) fase de crise, caracterizada pelo período sintomático que se estende até o início do tratamento; 2) fase crônica, marcada pela constância, progressão e remissão do quadro de sinais e sintomas; e 3) fase terminal, que vai desde o momento em que a morte é uma possibilidade, até ela propriamente dita.

Arruda e Zannon (2002) e Castro e Piccinini (2002) apontam que o tratamento 
de doenças com características de cronicidade exige frequentes consultas médicas, de forma que se possa intervir na doença em atividade e prevenir comorbidades. Essa rotina demanda mudanças na vida tanto do paciente, quanto de familiares e, principalmente, do cuidador.

Pode-se perceber que passar por uma situação de doença crônica afeta a estruturação na vida da criança enferma e da família. Portanto, o enfrentamento se inicia com a notícia da doença e as mudanças na rotina, a família sofre com e pela criança e muitas vezes se sente culpada pela doença do filho.

$$
\text { Lazarus e Folkman }
$$

definiram coping (em português, enfrentamento) como "as constantly changing cognitive and behavioral efforts to manage specific external and/or internal demands that are appraised as taxing or exceeding the resources of the person", (p. 141). Também definido como "um conjunto de estratégias para lidar com ameaça iminente" (Gimenes, 1997, p. 112, citada por Arruda \& Zannon, 2002).

Folkman, Lazarus, Gruen e DeLongis (1986) distinguiram as estratégias de enfrentamento em dois

\footnotetext{
${ }^{1}$ Tradução livre: Mudanças constantes de esforços cognitivos e comportamentais para gerenciar demandas externas e/ou internas específicas que são avaliadas como sobrecarregando ou excedendo os recursos pessoais do indivíduo.
}

conjuntos: (1) enfrentamento focado no problema: quando a pessoa entra em contato com a situação causadora de estresse, tentando controlar, resolver e organizar, procurando modificar $\mathrm{O}$ problema estressor; (2) enfrentamento focado na emoção: quando a pessoa procura controlar sua resposta emocional causada pela situação estressante, podendo ser se afastando, esquivando, negando ou procurando comportamentos paliativos. Além dessas duas estratégias primordiais, recentemente outros autores, descritos a seguir, salientam que existem outras estratégias de enfrentamento, como, por exemplo, religiosidade, distração e busca de suporte social.

Schleder, Parejo, Puggina e Silva (2013) avaliaram em sua pesquisa que grande parte dos familiares que estão com um ente querido na UTI se apegam à espiritualidade, revelada pela espera de um milagre, pela obrigação de não perder a esperança e pela perspectiva de mudanças. Acreditam, com isso, que têm tido mais força para enfrentar a situação estressante. Já Sterken (1996) investigou as estratégias de enfrentamento dos pais de criança com câncer e observou que a principal estratégia utilizada era com foco na emoção.

O suporte social foi avaliado por Greening e Stoppelbein (2007) como fator importante na regulação emocional do 
enfrentamento. Observaram em seus participantes que os sintomas da ansiedade diminuíram quando procuravam apoio social e, também, que os pais cuidadores de crianças com câncer têm apresentado estratégias adaptativas à situação vivenciada, não se diferenciando da vivência de pais que não estão passando por processos de tratamento.

As estratégias de enfrentamento ajudam os cuidadores de crianças a enfrentarem as situações estressantes de forma a amenizar o sofrimento. Costa, Mombelli e Marcon (2009) analisaram o sofrimento psíquico das mães acompanhantes de crianças hospitalizadas, observaram que as mães utilizam estratégias particulares, ficando sozinhas, rezando, lendo e chorando, ou externas, procurando outras mães para conversar, brincar com o filho ou fazendo atividades que distraiam. Portanto, as estratégias são individuais, cada uma encontra uma forma de amenizar o sofrimento e preservar a saúde mental.

Almeida et al. (2006) procuraram compreender a experiência de assistência domiciliar prestada pela mãe da criança com doença crônica e dependente de cuidados complexos. Essas mães relataram compartilharem o sofrimento com os filhos, se sentirem inseguras, com dúvidas, vivenciando o medo da morte da criança, que recebiam pouca informação dos profissionais de saúde, viviam exclusivamente para os cuidados do filho, destacaram o medo do desconhecido na fase inicial e apareceram alguns relatos de terem pensado em desistir. Apontaram que a família se desorganiza em um primeiro momento e precisa buscar novas estratégias para se reorganizar e equilibrar, mas sentem dificuldade em se reestabelecer, pois se desestruturam emocionalmente.

Em contrapartida, neste estudo, apareceram relatos de mecanismos de enfrentamento benéficos, como a paciência, força interior, coragem para lidar com a situação e o sentimento de vitória que surgia em alguns momentos de melhora. Os autores ratificaram que o vínculo mãe-filho aumenta no cuidado da criança com doença crônica e que o bemestar de um afeta o outro. Apesar de hoje existirem tratamentos modernos e tecnológicos para cuidar de determinados casos complexos, o sofrimento vivido pelo enfermo e a família se alonga e não há o devido suporte psicológico para essas pessoas.

É importante que a inserção da mãe e/ou cuidador da criança no contexto de cuidado e internação da criança seja realizada de modo gradativo e com acompanhamento de profissionais. Assim, é proporcionado ao cuidador um maior contato com a situação, de forma que 
dúvidas sejam sanadas, cuidados aprendidos e maior apoio psicológico para evitar possíveis comorbidades (Kohlsdorf \& Costa Junior, 2009; Pereira \& Kohlsdorf, 2014).

No estudo de Andraus, Minamisava e Munari (2004) foi observado que o enfrentamento do cuidador da criança hospitalizada se inicia quando a mãe percebe que deve cuidar do filho e ficar com ele na rotina do hospital. A vivência da mãe no dia a dia da hospitalização é permeada por preocupação, sofrimento, mudanças na dinâmica familiar e atitudes de conformação e apoio em um Ser Supremo. A mãe sofre com e pela criança por não conseguir acabar com a dor do filho e também sofre por não ter o devido apoio da equipe de saúde, o que dificulta o enfrentamento diante da situação estressante.

Beltrão, Vasconcelos, Pontes e Albuquerque (2007) estudaram as percepções maternas e estratégias de enfrentamento frente ao diagnóstico de câncer infantil. Observaram que as atitudes e sentimentos revelados na descoberta da doença foram descritos como chocante, dolorosa, experiência única, desesperadora e traumática. As mães relataram vontade de morrer e o medo do decorrer e desfecho do tratamento.

As integrantes desse estudo participaram da admissão social, que é uma reunião com os profissionais de saúde composta por uma médica, um psicólogo, um assistente social e uma enfermeira, de forma que sanassem as dúvidas dessas mães. Após essa reunião, as participantes se sentiram acolhidas e confiantes para participar dos cuidados ao filho. Essa experiência da admissão social confirma que o suporte da equipe de saúde e o relacionamento com outras mães que passam pela mesma situação são essenciais para o enfrentamento dos cuidadores das crianças hospitalizadas.

Além da questão do enfrentamento, acompanhar uma criança durante internação também pode apresentar ao cuidador manifestações importantes de perturbações psicológicas, como depressão e ideação suicida (Beltrão et al., 2007). A palavra depressão é, geralmente, utilizada para se referir ao estado da tristeza, a um sintoma, a uma síndrome ou a uma doença. Quando relacionada a uma síndrome, inclui alterações do humor, alterações cognitivas, psicomotoras e vegetativas. Quando referida a uma doença, é citada como transtorno depressivo maior, melancolia, distimia, depressão integrante do transtorno bipolar tipos I e II, depressão como parte da ciclotimia, etc. (Porto, 1999).

Nesse estudo, trataremos do termo empregado para sintoma. De acordo com o autor, a depressão enquanto sintoma pode 
aparecer em doenças clínicas, transtorno de estresse pós-traumático, demência e como resposta a situações estressantes ou a circunstâncias sociais e econômicas atribuladas.

Segundo Porto (1999), quando diagnosticada a depressão, consideram-se os sintomas psíquicos, fisiológicos e evidências comportamentais. Os sintomas psíquicos incluem humor deprimido; redução da capacidade de experimentar prazer na maior parte das atividades, antes consideradas como agradáveis (anedonia); fadiga ou sensação de perda de energia e a diminuição da capacidade de pensar, de se concentrar ou de tomar decisões. Os sintomas fisiológicos são a alterações de sono; alterações do apetite e redução do interesse sexual. Evidências comportamentais abrangem retraimento social; crises de choro; retardo psicomotor e lentificação generalizada, ou agitação psicomotora e comportamentos suicidas.

Tendo essa definição de depressão, Rezende, Derchain, Botega, Sarian, Vial e Morais (2005) avaliaram depressão e ansiedade nos cuidadores de mulheres em fase terminal de câncer de mama e ginecológico. Esses cuidadores eram em sua maioria filhas das pacientes. Como resultado, observaram que mais da metade apresentava depressão $(53,4 \%)$ e altas taxas de ansiedade. Em outro estudo com temática similar, Pegoraro e Caldana
(2008) identificaram que 6 dos 9 familiares de usuários de drogas entrevistados apresentam sofrimento psíquico, dentre eles depressão. Ou seja, mais da metade sofre de depressão.

$$
\text { Camargo, Lacerda, Viana, Pinto e }
$$
Fonseca (2009) avaliaram a sobrecarga do cuidador de crianças com paralisia cerebral através da escala Burden Interview. Constataram que não há uma sobrecarga muito alta dos cuidadores da pesquisa. Observaram que quanto menor a condição socioeconômica, maior a sobrecarga dos cuidadores. Além de que, cuidadores de crianças com uma menor limitação motora apresentam uma maior sobrecarga do que os cuidadores de crianças com comprometimentos mais graves. Porém, diferentemente dos autores citados, Pereira e Kohlsdorf (2014) avaliaram que apenas 10 dos 27 pais avaliados apresentaram depressão no contexto similar de cuidados a crianças com paralisia cerebral.

Não são incomuns ideações suicidas, tentativas de suicídio e o ato consumado diante de situações críticas, como o acompanhamento de uma internação pediátrica (Botega, 2014). Uma pessoa deprimida, ao ter distorções cognitivas, percebe qualquer obstáculo como irreversível e deseja pôr fim ao sofrimento diante de uma situação estressante que considera ser interminável. Esses pensamentos suicidas variam desde a 
vontade de morrer até a programação de se matar (Botega, 2014).

Dentre os diversos impactos que a doença crônica traz aos cuidadores, está a necessidade de a mãe abandonar o emprego, mudar o papel de esposa e de cuidadora do lar de forma a direcionar sua atenção ao filho enfermo. Essas mudanças aumentam a chance de sobrecarga emocional, conflitos conjugais, agressividade, isolamento social, depressão, dependência em remédios, entre outros. Portanto, o suicídio não é incomum nesse grupo de pessoas, pois as consequências que o cuidado à uma criança com doença crônica acarreta são graves e depende de como cada pessoa lida com a situação (Castro \& Piccinini, 2002; Lopez \& Stuhler, 2008).

Rapeli (2001) identificou em seu estudo que $78 \%$ dos participantes que tentaram suicídio relataram pelo menos uma dificuldade psicossocial que influenciou na tentativa de suicídio. Esses estressores psicossociais não envolvem apenas problemas conjugais, dificuldades para lidar com os filhos, brigas com amigos, discussões com os pais, etc., mas sim a dificuldade de a pessoa encontrar outras possibilidades para resolver os problemas, vendo como única saída a autoagressão (Rapeli, Cais \& Botega, 2004). Um fator observado que dificulta a elaboração de outras formas de sair dessas situações estressantes é a ausência de uma rede de apoio (Rapeli, 2001).

Tendo em vista a relevância de pesquisas neste contexto e com as temáticas descritas, este estudo tem como objetivo verificar estratégias de enfrentamento e ideação suicida em cuidadores de crianças com doença crônica em processo de hospitalização em um hospital pediátrico de atenção secundária e terciária.

\section{Método}

\section{Participantes}

Participaram do estudo cuidadores, assim entendidos como aqueles que cuidam, podendo ser familiar ou amigo, de crianças com doença crônica internadas em um hospital pediátrico terciário, totalizando 15 participantes que responderam Escalas Beck de depressão e ideação suicida. Desses, 8 foram escolhidos para a entrevista, com foco em identificar as estratégias de enfrentamento utilizadas. Os participantes que responderam à entrevista o fizeram por estarem em momento propício e viável para a atividade, sem cuidados à criança no momento nem presença de outros profissionais realizando procedimentos de saúde. Todos foram escolhidos por 
conveniência, a partir do contato direto com os cuidadores no hospital. Como critério de inclusão, os participantes deveriam ter crianças com diagnóstico de doença crônica que estivessem em processo de hospitalização, terem idade entre 18 e 80 anos e terem cursado, pelo menos, até o ensino fundamental. Como a Tabela 1

Participantes, Procedimento e Características dos Cuidadores.

\begin{tabular}{|c|c|c|c|c|c|c|}
\hline \multirow[t]{2}{*}{ Participantes } & \multirow[t]{2}{*}{ Procedimento } & \multicolumn{2}{|l|}{ Idades } & \multirow[t]{2}{*}{ Escolaridade } & \multirow[t]{2}{*}{ Sexo } & \multirow[t]{2}{*}{ Parentesco } \\
\hline & & Cuidador & Criança & & & \\
\hline Participante 1 & Apenas inventários & 18 & 4 & Ens. Médio & $\mathrm{F}$ & Mãe \\
\hline Participante 2 & Apenas inventários & 25 & 3 meses & Ens. Fundamental & $\mathrm{F}$ & Mãe \\
\hline Participante 3 & Entrevista e inventários & 46 & 2 & Ens. Fundamental & M & Pai \\
\hline Participante 4 & Entrevista e inventários & 46 & 6 & Ens. Superior & $\mathrm{F}$ & Avó \\
\hline Participante 5 & Entrevista e inventários & 40 & 7 & Ens. Fundamental & M & Pai \\
\hline Participante 6 & Entrevista e inventários & 42 & 6 & Ens. Fundamental & $\mathrm{F}$ & Mãe \\
\hline Participante 7 & Apenas inventários & 44 & 3 & Ens. Fundamental & $\mathrm{F}$ & Mãe \\
\hline Participante 8 & Entrevista e inventários & 18 & 4 meses & Ens. Fundamental & $\mathrm{F}$ & Mãe \\
\hline Participante 9 & Entrevista e inventários & 40 & 9 meses & Ens. Superior & $\mathrm{F}$ & Mãe \\
\hline Participante 10 & Apenas inventários & 18 & 3 meses & Ens. Fundamental & $\mathrm{F}$ & Mãe \\
\hline Participante 11 & Apenas inventários & 49 & 5 & Ens. Médio & $\mathrm{F}$ & Mãe \\
\hline Participante 12 & Apenas inventários & 34 & 1 & Ens. Fundamental & $\mathrm{F}$ & Mãe \\
\hline Participante 13 & Entrevista e inventários & 26 & 3 meses & Ens. Médio & $\mathrm{F}$ & Mãe \\
\hline Participante 14 & Apenas inventários & 34 & 1 & Ens. Fundamental & $\mathrm{F}$ & Mãe \\
\hline Participante 15 & Entrevista e inventários & 20 & 3 & Ens. Fundamental & $\mathrm{F}$ & Mãe \\
\hline
\end{tabular}

Local identidade pessoal é sigilosa, chamaremos aqui os participantes por números. A tabela 1 apresenta os participantes, indicando qual foi o procedimento utilizado com cada um, idades do cuidador e da criança, escolaridade, sexo e grau parentesco com a criança internada:
As entrevistas foram realizadas no hospital, ficando a critério do cuidador 
permanecer ao lado do leito ou em outro ambiente. O hospital em tela é referência nos cuidados à saúde da mulher e da criança. Tem como missão coordenar e executar ações de promoção, proteção e recuperação da saúde, ensino, pesquisa e gestão de acordo com as premissas do Sistema Único de Saúde (SUS). O hospital funciona desde 1966 e conta com 270 leitos divididos em obstetrícia, ginecologia, pediatria e berçário patológico e clínica médica (Secretaria de Estado de Saúde do Distrito Federal, 2016).

\section{Instrumentos}

Foram utilizados um roteiro de entrevista semiestruturado para abordar estratégias de enfrentamento utilizadas pelos pais, folha de respostas do Inventário de Depressão de Beck (BDI) e do Inventário de Ideação Suicida de Beck (BSI). A entrevista foi conduzida pela pesquisadora e os inventários foram administrados oralmente pela mesma para evitar quaisquer más interpretações devido à baixa escolaridade de alguns participantes.

O roteiro de entrevista semiestruturado foi elaborado para esta pesquisa, com a intenção de obter informações sobre estratégias de enfrentamento que o cuidador utilizou quando soube do diagnóstico e que utiliza atualmente, além de conhecer a rotina, suas mudanças e as maiores dificuldades enfrentadas.

O Inventário de Depressão de Beck é uma escala de auto-relato que avalia a intensidade dos sintomas da depressão. Consiste em 21 itens que apresentam atitudes e sintomas com escores que variam entre 0 e 3 , que indicam o grau de depressão em quatro níveis: leve, mínimo, moderado e severo. $\mathrm{O}$ escore total representa a soma dos escores individuais dos itens, que indica o grau de intensidade da depressão (Cunha, 2001).

O Inventário de Ideação Suicida de Beck é uma escala de auto-relato que investiga ideação suicida. Contém 21 itens, sendo que os primeiros 19 apresentam três alternativas de respostas que indicam progressões do agravamento de desejos, atitudes e planos suicidas. Os dois últimos itens não fazem parte do somatório do escore final, têm somente o intuito de obter informações sobre o número de tentativas de suicídio e a seriedade da vontade de morrer na última delas (Cunha, 2001).

\section{Procedimentos}

O projeto foi inicialmente aprovado pelo Comitê de Ética em Pesquisa da Fundação de Ensino e Pesquisa em Ciências da Saúde (FEPECS) sob protocolo 131415. O contato com os 
participantes foi feito no próprio hospital no local de internação. A cada participante foi explicado sobre a pesquisa, apresentado o Termo de Consentimento Livre e Esclarecido - TCLE (Anexo B) e, quando consentido, iniciada a entrevista e aplicados os Inventários de Depressão e de Ideação Suicida de Beck.

\section{Análise dos dados}

A análise dos dados foi feita pela proposta de Bardin (2009) e a correção do Inventário de Depressão de Beck e do Inventário de Ideação Suicida de Beck utilizando o Manual da versão em português das Escalas Beck (Cunha, 2001). Foram elaboradas três categorias analíticas temáticas para construção dos resultados, a fim de orientar a análise das entrevistas, são elas: estratégias de enfrentamento, depressão e ideação suicida.

\section{Resultados e Discussão}

A seguir serão apresentados e discutidos os resultados mais relevantes da pesquisa, considerando as categorias analíticas mencionadas anteriormente. Com propósito de tornar a discussão dos dados mais clara, serão apresentadas as comparações com dados da literatura nesta mesma seção, reunindo, portanto, Resultados e Discussão.

\section{Estratégias de Enfrentamento}

A análise de estratégias de enfrentamento foi realizada por meio de entrevistas apenas com 8 participantes. Em todas as entrevistas apareceram relatos foco no problema (Tabela 2), o que, como Folkman et al., (1986) apresentaram, ocorre quando a pessoa entra em contato com a situação estressora, tentando controlar, resolver e organizar. Os participantes apontaram que eles próprios não conseguem resolver o problema da criança, mas relataram estar sempre indo atrás de medicamentos, equipamentos e se inteirar sobre os cuidados que devem ter com ela para que possam controlar ou modificar a situação. 


\section{Tabela 2}

Estratégias de Enfrentamento Descritas pelos Participantes em Ordem de Prioridade.

\begin{tabular}{ll}
\hline Participantes & Estratégias de enfrentamento \\
\hline 3 & Religioso e foco no problema \\
4 & Religioso e foco no problema \\
5 & Religioso, foco no problema e distração \\
6 & Religioso, foco no problema e distração \\
8 & Religioso, foco no problema e social \\
9 & Social, religioso e foco no problema \\
13 & Religioso e foco no problema \\
15 & Social e foco no problema
\end{tabular}

Dos 8 entrevistados, 7 indicaram que utilizam como estratégia de enfrentamento o foco na religião. Sendo que a participante 9 indicou essa estratégia como secundária, pois primeiramente procura suporte social e pede ajuda religiosa dos amigos e familiares ("eu tenho um grupo (no celular), dai eu falo lá "reza aí, gente”, eu mesma rezo pouco (...) eu tenho mais um suporte social, falo no whatsapp, mando vídeo, fotos"). Em diversos momentos relatou confiar em Deus, colocar nas mãos Dele e conforme relato: "Deus sabe o que faz, se me deu esse (filho) é porque sabe que eu vou conseguir".

O participante 3 expôs "temos muita fé e acreditamos muito em Deus (...) família também ajuda, mas a principal é Deus". Essa fala foi muito repetida pelos outros participantes, em que focam na religião como forma de confiar que a situação da criança vai melhorar. Schleder et al. (2013) também observaram o foco na religião na maior parte dos seus participantes da pesquisa. Grande parte dos familiares que estão com um parente na UTI se apegam à espiritualidade, apontando como esperando por um milagre, a obrigação de não perder a esperança e a expectativa por mudanças. Acreditam que têm tido mais força para enfrentar a situação estressante. $O$ que também é evidenciado nesta pesquisa com o relato, por exemplo, do participante 5: "eu entrego na mão Dele, que possa fazer um milagre com ele" quando questionado como se sente hoje.

Assim como, Andraus et al. (2004) avaliaram que a vivência da mãe na rotina da hospitalização é permeada por preocupação, sofrimento, mudanças na 
dinâmica familiar e atitudes de conformação e apoio em um Ser Supremo.

Apenas a participante 15 não mencionou religiosidade como uma estratégia de enfrentamento. Quando questionada, relatou ter religião, mas que há muito tempo não frequenta a igreja e não reza, e, portanto, não pede a Deus pela melhora do filho como os demais participantes. Disse se apoiar no contexto social, conversando com amigos e familiares para se acalmar: "igual ontem, foi um sufoco aqui... comecei a desesperar, daí o "povo" me ligou e me acalmou mais, entende?". Também, focaliza no manejo do problema, em que procura ter condições financeiras para comprar medicamentos e mudar o ambiente em que moram, pois não favorece na saúde da filha, que necessita viver em um local limpo.

O suporte social foi avaliado por Greening e Stoppelbein (2007) como fator importante na regulação emocional. Observaram em seus participantes que os sintomas da ansiedade diminuíam quando procuravam apoio social. $\mathrm{Na}$ presente pesquisa também foi evidenciado que o suporte social é um fator importante para alguns cuidadores, assim como aponta a fala da participante 15 relatada acima.

Sobre suporte familiar e de amigos, foi exposto por alguns entrevistados que familiares e amigos se afastaram. A fala do participante 5 corrobora isto: " $O$ aprendizado que a gente tem lá fora é ilusão, porque quando a gente tá aqui dentro aquelas amizades de antes somem, some todo mundo (...) ficam com medo, assustados, sei lá". Os participantes 4, 6, e 13 também relataram terem se afastado de muitos amigos e familiares desde que entraram na rotina de hospitalização com a criança.

Diferentemente desta pesquisa e dos estudos de Schleder et al. (2013) e também Andraus et al. (2004), Sterken (1996) investigou as estratégias de enfrentamento dos pais de criança com câncer e observou que a principal estratégia utilizada é com foco na emoção.

Apenas dois participantes (5 e 6) apontaram como uma estratégia a distração, que é uma forma de cuidado paliativo focado na emoção. O participante 5 disse focar no trabalho e no cuidado com os outros filhos e a participante 6 relatou se distrair lendo ou assistindo televisão. Os demais participantes relataram não conseguirem focar em atividades como essas, procurando apenas conversar com outras mães por perto ou telefonar para familiares e amigos.

Assim como no estudo de Costa et al. (2009), foi observado que as mães utilizam estratégias particulares para amenizar o sofrimento. Como já mencionado, o relato mais recorrente foi religioso, em que se apegam a um Ser 
Superior, porém apareceram relatos, também, com outros focos. A participante 8 referiu "quando eu cheguei aqui, eu conheci outras mães com filhos também com cardiopatia e pensei 'poxa não sou só eu que tô passando por isso' e fui conhecendo outros casos piores que o meu" o que apontou como reconfortante, por fazer amizades com pessoas passando pela mesma situação e trocando informações. As participantes 9 e 13 também descreveram o contato com outras mães como importante e produtor de alívio e suporte, o que também apareceu nas pesquisas de Beltrão et al. (2007) e Costa et al. (2009), que avaliaram a relação com pessoas em situação de cuidados à criança com doença crônica como fator protetivo.

Os participantes apontaram como dificuldades enfrentadas no momento a falta de dinheiro, o afastamento do restante da família, a rotina de trabalho (evidenciando que a maior parte largou o emprego) e a espera por alguma melhora do quadro da criança. Todos esses pontos referidos mostram o quanto a dinâmica familiar se desorganiza e a necessidade de os cuidadores buscarem novas estratégias para se reorganizarem (Almeida et al., 2006).

Quando questionados sobre como se sentiram quando souberam do diagnóstico, descreveram os sentimentos de que iriam perder o filho, doloroso, desesperador, assustador e impactante. A participante 13 relatou "fiquei desesperada. Quando eu soube, achei que ia perder ela, que nem o outro", havia perdido o primeiro filho há 1 ano e meio pelo mesmo diagnóstico, porém só foi descoberto após o óbito, por isso estava motivada a estudar sobre a doença e prestar todo cuidado necessário, evidenciando o foco no problema neste momento.

Sobre como se sentem hoje, apareceram relatos de se sentirem mais tranquilos, felizes e tristes. A participante 8 relatou "hoje eu tô muito feliz, tô do lado do meu filho. Achei que isso nunca ia acontecer, achei que já ia perder ele" e a 13 apontou que está triste, mas mais tranquila, referindo estar mais adaptada à rotina. A participante 4 referiu estar bem, apenas aguardando a melhora do neto para irem para casa.

As falas dessas participantes condizem com a pesquisa de Greening e Stoppelbein (2007) que apontaram que os pais que cuidam de crianças com câncer têm apresentado estratégias adaptativas à situação vivenciada, não se diferenciando da vivência de pais que não estão passando por processos de tratamento.

A participante 15, entretanto, se destacou, referindo que "hoje não mudou nada, sofro do mesmo jeito, muito desânimo", evidenciando uma atitude depressiva, de desesperança, e com 
estratégias

de

enfrentamento

Depressão

desfavoráveis.

Como foi observado nesta pesquisa

O Inventário de Depressão de Beck e no estudo de Andraus et al. (2004), os (BDI) avaliou o nível de depressão dos cuidadores sofrem com e pela criança e vivenciam uma rotina bastante estressante. Por isso, assim como Kohlsdorf e Costa Junior (2009) e Pereira e Kohlsdorf (2014) indicaram, é importante o devido acompanhamento da equipe multiprofissional de saúde não apenas à criança, mas também ao cuidador, de forma que o aproximem do contexto de cuidados e faça com que se sintam acolhidos.

O olhar atento dos profissionais do hospital foi elogiado pelos participantes, o que pode ser um indicativo de a maioria dos entrevistados terem apresentado estratégias de enfrentamento adaptativas. 
Tabela 3

Pontuação e Classificação de Depressão para cada Participante.

\begin{tabular}{lll}
\hline Participantes & Pontuação & Classificação \\
\hline 1 & 11 & Depressão leve \\
2 & 13 & Depressão leve \\
3 & 5 & Depressão mínima \\
4 & 8 & Depressão mínima \\
5 & 5 & Depressão mínima \\
6 & 9 & Depressão mínima \\
7 & 6 & Depressão mínima \\
8 & 8 & Depressão mínima \\
9 & 8 & Depressão mínima \\
10 & 11 & Depressão leve \\
11 & 34 & Depressão severa \\
12 & 18 & Depressão moderada \\
13 & 16 & Depressão leve \\
14 & 12 & Depressão leve \\
15 & 47 & Depressão severa \\
\hline
\end{tabular}

Observa-se que dos 15 participantes, 7 têm depressão mínima, 5 depressão leve; 1 depressão moderada e 2 depressão grave. Portanto, a maioria não apresenta nível de depressão significativo, diferente do estudo feito por Rezende et al. (2005), que indicou que mais da metade dos cuidadores de mulheres em fase fora de possibilidades terapêuticas de cura para câncer de mama e ginecológico apresentavam depressão. Assim como, Pegoraro e Caldana (2008) avaliaram que mais da metade de familiares de usuários de drogas apresentam algum nível de depressão.
Em contrapartida, concordando com essa pesquisa, Camargo et al. (2009) analisaram o nível de sobrecarga em cuidadores de crianças com paralisia cerebral e constataram que a sobrecarga nesses cuidadores não é elevada, o que acreditam ser devido ao suporte social.

Do mesmo modo, Pereira e Kohlsdorf (2014) apresentaram como um dos resultados da pesquisa sobre ansiedade, depressão e qualidade de vida de pais, no tratamento da paralisia cerebral infantil, que a depressão e a ansiedade não proporcionaram índices elevados, sugerindo que a rotina e cuidados não 
interferem de forma relevante na saúde mental desses pais.

Alguns itens do questionário chamaram atenção. No item 1, que se refere ao sentimento de tristeza, 12 participantes se referiram como "eu me sinto triste", 1 marcou "não me sinto triste" e 2 marcaram "estou sempre triste e não consigo sair disto". Estas duas são as mães classificadas com depressão grave. Ao apontarem que se sentem tristes, se referiam a estarem novamente com a criança internada, ou, em alguns casos, por estarem há meses ou anos nesta situação. Este resultado salienta o que já era esperado e o que outros autores, como Camargo et al. (2009) e Pereira e Kohlsdorf (2014) apontaram como importante fator a ser avaliado na saúde dos principais cuidadores, pois, a depender do nível de tristeza, que é medido com o BDI, torna-se necessária uma atenção especial a eles.

O item 3 avalia o sentimento de fracasso pessoal. Treze participantes indicaram que não se sentem um fracasso, um participante acredita que fracassou mais do que uma pessoa comum e outro acredita que é um completo fracasso. Estes dois participantes a se classificarem de forma diferente da maioria são, novamente, as duas mães que indicaram depressão grave. A questão 5 aborda sobre o sentimento de culpa, em que 13 classificaram não se sentirem culpados e somente as duas com depressão grave marcaram o item "eu me sinto sempre culpado".

Quanto à frequência de choro, apareceram relatos diferentes. Cinco participantes relataram não chorarem mais do que o habitual, cinco choram mais agora do que costumavam, três choram o tempo todo e dois apontaram que agora não conseguem mais chorar, por mais que queiram.

Diferente de Camargo et al. (2009) que apontaram que, quanto menor a condição socioeconômica, maior a sobrecarga dos cuidadores, e Castro e Piccinini (2002), que em sua revisão de literatura identificaram que a condição crônica e a idade em que descobriram o diagnóstico interferem nos fatores psicológicos, comportamentais e sociais dos cuidadores, nesta pesquisa não foi evidenciada influência de escolaridade, sexo do cuidador, idade do cuidador, idade da criança e grau de parentesco sobre o nível de depressão dos participantes. As duas participantes (11 e 15$)$ que apresentaram depressão severa têm idade e escolaridade distintas e sabem do diagnóstico desde o nascimento, ou seja, há 5 e 3 anos, respectivamente. O mesmo ocorreu com os participantes que apresentaram depressão leve e com os demais participantes que apresentaram 
sinais mínimos de depressão, evidenciando que os dados sociodemográficos não influenciam na saúde mental dos cuidadores.

\section{Ideação Suicida}

A aplicação do Inventário de Ideação Suicida (BSI) consistiu em identificar se há pensamento suicida nos cuidadores das crianças com doença crônica. A Tabela 4 apresenta os dados obtidos nesta temática.

\section{Tabela 4}

Pontuação em Ideação Suicida.

\begin{tabular}{lll}
\hline Participantes & Pontuação & Ideação Suicida \\
\hline 1 & 0 & Não \\
2 & 0 & Não \\
3 & 0 & Não \\
4 & 0 & Não \\
5 & 0 & Não \\
6 & 0 & Não \\
7 & 0 & Não \\
8 & 0 & Não \\
9 & 0 & Não \\
10 & 0 & Não \\
11 & 3 & Sim \\
12 & 0 & Não \\
13 & 0 & Não \\
14 & 0 & Não \\
15 & 14 & Sim \\
\hline
\end{tabular}

A ideia de se matar apareceu em duas participantes, 11 e 15, as mesmas classificadas com depressão grave. Porém, apenas a 15 respondeu o inventário até o item 21, pois já apresentou desejo de se matar, não evitaria a morte em situação de risco e já tentou suicídio duas vezes. A participante 11, no BDI, apontou no item 9 que tem ideias de se matar, mas não as executaria, portanto, no BSI foi contraditório, pois relatou não ter desejo de se matar (item 4) e que tentaria se salvar 
em situação de risco de vida (item 5), que definem se o questionário deve continuar a ser respondido. Essa contradição pode ser devido ao fato de que o esposo chegou no momento de iniciar essas questões, o que pode tê-la deixado retraída. Foi observada a mudança de comportamento na presença do esposo, por isso a entrevistadora ofereceu para continuarem em outro local e a participante não quis.

Quando realizado o inventário com os demais participantes, em unanimidade relataram acharem absurda a ideia de se matar, pois não abandonariam o filho enfermo com o argumento de "ele depende de mim" (participante 13).

Castro e Piccinini (2002) e Lopez e Stuhler (2008) concluíram em suas pesquisas que o papel dos pais, de cuidador de criança com doença crônica, traz tantas mudanças na dinâmica e rotina familiar que casos de suicídio não são incomuns nesse grupo. Este estudo, apesar da restrita amostra, confirmou que podem existir pensamentos suicidas nesses cuidadores e que essas ideações surgem pela limitação de os cuidadores identificarem outras formas de lidar com a rotina de hospitalizações e cuidados (Rapeli et al., 2004).

Rapeli (2001) identificou que um fator que impede a elaboração de outras formas de sair de situações estressantes é a ausência de uma rede de apoio. Nesta pesquisa, foi relatada por alguns pais a restrita rede de apoio, porém, também, apareceram relatos de rede de apoio sociofamiliar favoráveis. A participante 15 , com alto nível de depressão e ideação suicida, relatou ter a rede de apoio muito escassa, sendo ela a única cuidadora da filha e ninguém a substitui nas tarefas domiciliares quando está com a criança hospitalizada.

Não foram evidenciadas associações estatisticamente significativas entre os escores do BDI, BSI e os dados sociodemográficos (idade do cuidador, idade da criança e escolaridade).

\section{Considerações Finais}

Este trabalho contribuiu para avaliar as estratégias de enfrentamento utilizadas por cuidadores de criança com doença crônica, o nível de depressão e se há ideação suicida. Foram constatados diversos relatos, e, desses se sobressaíram as estratégias de enfrentamento focadas na religião e o baixo nível de depressão nos participantes.

Os resultados desta pesquisa permitiram observar que, de forma geral, os cuidadores de crianças com doença crônica apresentam estratégias de enfrentamento adaptativas à situação vivenciada. Este dado pode ser devido ao apoio que a equipe de profissionais do 
hospital tem prestado a esses cuidadores, além do suporte na religiosidade relatado pela maioria dos participantes. Há a possibilidade de que, em decorrência de já estarem há anos ou meses vivenciando a experiência de hospitalização, estejam mais acostumados à rotina, de forma que não se abalam com tanta intensidade como outros cuidadores que a estejam iniciando.

Com base nos resultados, pode-se observar que os participantes não apresentaram altos níveis de depressão e ideação suicida. A ocorrência foi constatada em apenas duas participantes. Há diversas possibilidades que podem ter influenciado no baixo índice de depressão nos cuidadores de criança com doença crônica, como: a possibilidade de alguns participantes terem ficado receosos ao responderem com sinceridade sobre sua vivência no papel de cuidador; o fato de a entrevistadora ter tido que ler os itens do Inventário e o fato de todos os participantes já terem contato com o diagnóstico há, pelo menos, 3 meses e não ser mais tão recente a rotina de hospitalização e cuidados, algo que foi relatado por alguns participantes, por exemplo, como a participante 8 apontou "quando eu soube eu só chorava e não queria falar e nem ver ninguém".
As duas participantes que apresentaram alto índice de depressão e ideação suicida foram encaminhadas para o atendimento psiquiátrico e, se não estavam sendo acompanhadas por psicólogos, foi feito um pedido de parecer (documento específico que solicita atendimento pontual do profissional).

Assim sendo, conclui-se com este estudo que a boa relação e comunicação entre os profissionais e os cuidadores é de grande relevância para que mantenham a boa saúde mental e encontrem estratégias de enfrentamento adaptativas. Portanto, deve-se sensibilizar os profissionais a se envolverem no processo de hospitalização junto a esses cuidadores.

A amostra reduzida e o pouco tempo para levantamento de dados podem ter sido fatores limitantes para esta pesquisa. Portanto, considera-se importante a realização de pesquisas com maior número de participantes, aprofundando mais nas estratégias de enfrentando e podendo, inclusive, serem comparados grupos de cuidadores de criança com doença crônica e cuidadores de criança sem doença crônica. 


\section{Referências}

Almeida, M. I.; Higarashi, I. H.; Molina, R. C. M.; Marcon, S. S. \& Vieira, T. M. M. (2006). O ser mãe de criança com doença crônica. Escola Anna Nery Revista de Enfermagem, 10(1), 36-46. https://doi.org/10.1590/S1414-81452006000100005.

Andraus, L. M.; Minamisava, R. \& Munari, D. B. (2004). Cuidando da família da criança hospitalizada. Revista Brasileira Crescimento Desenvolvimento Humano, 14(2). 50-54 https://doi.org/10.7322/jhgd.40057.

Arruda, P. M. \& Zannon, C. M. L. C. (2002). Tecnologia Comportamental em Saúde: Adesão ao tratamento pediátrico da doença crônica: evidenciando o desafio enfrentado pelo cuidador. Santo André: ESETec.

Bardin, L. (2009). Análise de Conteúdo. Lisboa, Portugal; Edições 70, LDA. Original publicado em 1974.

Barros, L. (2003). Psicologia Pediátrica: Perspectiva Desenvolvimentista. Lisboa: Climepsi.

Beltrão, M. R. L. R.; Vasconcelos, M. G.; Pontes, C. M. \& Albuquerque, M. C. (2007). Câncer infantil: percepções maternas e estratégias de enfrentamento frente ao diagnóstico. Jornal de Pediatria, 83(6), 562-566. https://doi.org/10.1590/S002175572007000800014.

Botega, N. J. (2014). Comportamento suicida: epidemiologia. Psicologia USP, 25(3), 231236. https://doi.org/10.1590/0103-6564D20140004.

Camargo, A. C. R.; Lacerda, T. T. B.; Viana, S. O.; Pinto, L. R. A. \& Fonseca, M. L. S. (2009). Avaliação da Sobrecarga do cuidador de crianças com paralisia cerebral através da escala Burden Interview. Revista Brasileira de Saúde Materno Infantil, 9(1), 31-37. https://doi.org/10.1590/S1519-38292009000100004.

Castro, E. K. (2007). Psicologia Pediátrica: A Atenção à Criança e ao Adolescente com Problemas de Saúde. Psicologia, Ciência e Profissão, 27 (3), 396-405. https://doi.org/10.1590/S1414-98932007000300003.

Castro, E. K. \& Bornholdt, E. (2004). Psicologia da Saúde X Psicologia Hospitalar: Definições e Possibilidades de Inserção Profissional. Psicologia, Ciência e Profissão, 24(3), 48-57. https://doi.org/10.1590/S1414-98932004000300007.

Castro, E. K \& Piccinini, C. A. (2002). Implicações da doença crônica na infância para as relações familiares. Psicologia: Reflexão e Crítica, 15(3), 625-635. https://doi.org/10.1590/S0102-79722002000300016.

Costa, J. B.; Mombelli, M. A. \& Marcon, S. S. (2009). Avaliação do Sofrimento Psíquico da Mãe Acompanhante em Alojamento Conjunto Pediátrico. Estudos de Psicologia, 26(3), 317-325. https://doi.org/10.1590/S0103-166X2009000300005.

Cunha, J. A. (2001). Manual da Versão em Português das Escalas Beck. São Paulo, Brasil: Casa do Psicólogo. 
Folkman, S; Lazarus, R. S.; Gruen, R. J. \& DeLongis, A. (1986). Appraisal, Coping, Health Status, and Psychological Symptoms. Journal of Personality and Social Psychology, 50(3), 571-579. https://doi.org/10.1037/0022-3514.50.3.571.

Greening, L. \& Stoppelbein, L. (2007). Brief Report: Pediatric Cancer, Parental Coping Style, and Risk for Depressive, Posttraumatic Stress, and Anxiety Symptoms. Journal of Pediatric Psychology, 32(10), 1272-1277. https://doi.org/10.1093/jpepsy/jsm057.

Kohlsdorf, M. \& Costa Junior, A. L. (2009). Enfrentamento entre Cuidadores de Pacientes Pediátricos em Tratamento de Leucemia. Interação em Psicologia, 13(2), 263-274. https://doi.org/10.5380/psi.v13i2.13103.

Lazarus, R. S. \& Folkman, S. (1984). Stress, Appraisal and Coping. New York: Springer Publishing Company.

Lopez, M. \& Stuhler, G. D. (2008). Atendimento Psicológico a Mães de Crianças com Doença Crônica: Relato de Experiência. Psicologia Argumento, 26(55), 341-347.

OMS, Organização Mundial de Saúde (2016). Constituição da Organização Mundial de Saúde (OMS/WHO). Retirado de http://www.direitoshumanos.usp.br/index.php/OMSOrganiza\%C3\%A7\%C3\%A3o-Mundial-da-Sa\%C3\%BAde/constituicao-daorganizacao-mundial-da-saude-omswho.html. https://doi.org/10.7213/rpa.v26i55.20071.

Pegoraro, R. F \& Caldana, R. H. L (2008). Sofrimento psíquico em familiares de usuários de em Centro de Atenção Psicossocial (CAPS). Interface - Comunicação, Saúde e Educação, 12(25), 295-307. https://doi.org/10.1590/S1414-32832008000200006.

Pereira, L. M \& Kohlsdorf, M. (2014). Ansiedade, Depressão e Qualidade de Vida de Pais no Tratamento da Paralisia Cerebral Infantil. Interação em Psicologia, 18(1), 37-46. https://doi.org/10.5380/psi.v18i1.28823.

Porto, J. A. D. (1999). Conceito e Diagnóstico. Revista Brasileira de Psiquiatria, 21(1), 611. https://doi.org/10.1590/S1516-44461999000500003.

Rapeli, C. B. (2001). Tentativas de Suicídio com Risco de Vida: Intencionalidade Suicida, Letalidade Médica e Análise de Agrupamentos (Tese de Doutorado). Universidade Estadual de Campinas, Campinas, São Paulo.

Rapeli, C. B.; Cais, C. F. S. \& Botega, N. J. (2004). Comportamento Suicida no Hospital Geral. Em B. G. W \& N. J. B (Org.), Comportamento Suicida (pp. 183-188). Porto Alegre: Artmed.

Rezende, V. L.; Derchain S. F. M.; Botega, N. J.; Sarian, L. O.; Vial, D. L. \& Morais, S. S. (2005). Depressão e ansiedade nos cuidadores de mulheres em fase terminal de câncer de mama e ginecológico. Revista Brasileira de Ginecologia e Obstetrícia, 27(12), 737743. https://doi.org/10.1590/S0100-72032005001200006.

Schleder, L. P; Parejo, L. S; Puggina, A. C \& Silva, M. J. P. (2013). Espiritualidade dos familiares de pacientes internados em unidade de terapia intensiva. Acta Paulista de Enfermagem, 26(1), 71-78. https://doi.org/10.1590/S0103-21002013000100012. 
Secretaria de Estado de Saúde do Distrito Federal. (2016). Hospital Materno Infantil de Brasília. Retirado de http://www.saude.df.gov.br/sobre-a-secretaria/hospitais-eregionais/264-regional-de-saude-da-asa-sul.html.

Spink, M. J. P. (1992). Psicologia da Saúde: A Estruturação de um novo campo de saber. Em F. C. B. Campos (Org.), Psicologia e Saúde - Repensando Práticas (11-21). São Paulo: Hucitec.

Sterken, D. J. (1996). Uncertainty and coping in fathers of children with cancer. Journal of Pediatric Oncology Nursing, 13 (2), 81-88.

Vieira, M. A. \& Lima, R. A. G. (2002). Crianças e adolescentes com doença crônica: convivendo com mudanças. Revista Latino-americana de Enfermagem, 10(4), 552-560. https://doi.org/10.1590/S0104-11692002000400013.

\section{As autoras:}

Gabriela Falleiros Wirth Chaibub possui graduação em Psicologia pelo Centro Universitário de Brasília. E.mail: gabriela.chaibub@gmail.com

Marina Kohlsdorf é doutora e mestre em Processos de Desenvolvimento Humano e Saúde pelo Programa de Pós-Graduação em Processos de Desenvolvimento Humano e Saúde, no Instituto de Psicologia da Universidade de Brasília. Professora no curso de Psicologia do Centro Universitário UniCeub nos cursos de graduação e mestrado em Psicologia. Colaboradora no Laboratório de Desenvolvimento em Condições Adversas - LADVERSA - na Universidade de Brasília (UnB). Editora associada da revista Psicologia: Reflexão e Crítica. E.mail: marinak@unb.br

Recebido em: 23/07/2017.

Aprovado em: 29/12/2017. 